\title{
Sustainable Planning of Supply Chains in Large-Scale Systems with Real Options Analysis
}

\begin{abstract}
Aidin Azari Marhabi ${ }^{1}$, Abdollah Arasteh ${ }^{2, *}$, Mohammad Mahdi Paydar ${ }^{3}$
This paper presents a structure that empower designing supervisory groups to survey the estimation of real options in projects of enormous scale, incompletely standardized frameworks actualized a couple of times over the medium term. Specific options writing is done using a methodology of planning the design and making prior decisions regarding the arrangements of specific options, with a recreation-based value measure designed to be near-current construction rehearsals and to resolve financial problems in particular cases. To study the case and demonstrate the actual application of this method, drug chain modeling at the tactical level was investigated. The physical and financial flow and their disturbance are simultaneously modulated. In order to complete the financial flow, financial ratios are also entered into the model. Problem uncertainty has been modeled using one of the most recent robust optimization approaches called Robust Possibilistic Programming (RPP) in combination with real options theory. The model was applied to a case study and its results were analyzed and validated by GAMS software. The results show that without violating the limitations of the problem, it shows appropriate decisions to deal with the problem.
\end{abstract}

Keywords: Sustainable planning, drug supply chain, real options theory, robust possibilistic programming

Manuscript was received on 28/10/2018, revised on 01/04/2019 and accepted for publication on 12/06/2019.

\section{Introduction}

Supply chain disruption after the September 11, 2001, attacks has attracted more attention. A disturbance is defined as an event that disrupts the flow of materials in the supply chain and results

\footnotetext{
* Corresponding author

${ }^{1}$ Masters Student, Department of Industrial Engineering, Babol Noshirvani University of Technology, Babol, Iran, E-mail: aidinak626@gmail.com

${ }^{2}$ Assistant Professor, Department of Industrial Engineering, Babol Noshirvani University of Technology, Babol, Iran, E-mail: arasteh@nit.ac.ir

${ }^{3}$ Associate Professor, Department of Industrial Engineering, Babol Noshirvani University of Technology, Babol, Iran, E-mail: paydar@ nit.ac.ir
} 
in a sudden interruption of the flow of products [68]. The exacerbations of supply chain vulnerability to disruption include competitive environment, increased complexity, outsourcing and partnerships, limited buffers, overcrowding, poor scheduling and execution [29], customer or supplier dependency, being a centralized or single source supplier and relying on global resources [48]. In the supply chains that typically deal with large-scale manufacturing and service systems, there are two contradictory concepts, and this paper has been written with a focus on both.

In the light of instinct alone, the framework for versatility and the design of the stage seem to be contending with ideal models: the stage is, all things considered, a ton of uniform pieces, curves, inventions and so on among a community of objects, which is typically costly to prepare and construct, and obliges the creation of new items and limited enhancement of existing ones. Truth be told, the hypopaper for this job is that the layout of the stage allows and crushes potential versatility concurrently and in different ways [34]. The two standards can be contending here and there and corresponding in others. Along these lines, there is a requirement for an organized procedure for simultaneous stage structure and flexibility plan.

The main focus of this paper is on the application of supply chain vulnerability. One of the most important factors in supply chain vulnerability is its globalization (that is, the vast extent), while in recent years the general trend of supply chains has become global [11]. Global supply chains in their course of action face different risks that can be divided into two main groups: the risks arising from internal supply chain relationships and the risks arising from it [24]. Supply chains must include in their decisions new purchases such as exchange rates, customs issues and such that increase uncertainty and thus the complexity of the decision-making environment [62]. In order to manage the potential disruption identified in the supply chain, the conditions and sources of the event, as well as their direct and indirect consequences, should be studied and considered as appropriate ways to deal with it. This research seeks to establish a multilevel global supply chain under conditions of disruption in both physical and financial flows, using robust feasibility planning in combination with a real options approach that has advantages over conventional possibility planning.

\subsection{Applications for consumer products and development programs}

A brisk investigates to the companies that lead their division of business that they have switched from providing a single item in huge amounts to dividing the design qualities of their object. These trends have been observed in purchasers ' products, such as Walkman and electrical appliances, as well as in high-innovative dynamic structures, such as commercial airships. Changing from "micro specialization" systems to "medium development" in the paradigm program also enabled organizations to take advantage of economies of scale, information sharing, smoother implementation of a greater number of variations, funding benefits and extra-part decreases. [34].

For purchaser products, the philosophy of the stage plan is normative in the light of simple and well-reported advantages. Given the high volume (or planned volume) of the production of an object unit, engineers expected to share the assumption that the system details would be consumed and the stage pieces would be integrated between all variations. The expense of upgrading the stage segments for each change is often held apart from, along such lines, the capital cost of producing changes and the underlying stage.

Step gains are also archived in the progress of large scale systems, e.g. oil inquiry and generation base. Standardization of parts and processes in such undertakings has culminated in double-digit decreases in capital costs, operation time, operability and feasibility. The following scholarly difficulty for stage strategists and scholars resides in the structure, progression and usage of time stages, the unusual environment of shifting customer preferences, expense details, object 
recognition and the growth of innovation. The stage system, i.e. the consistency and degree of the stage segments, must not only follow the static or deterministic criterion of optimality; it must allow the growth and adaptation of the entire organization to evolving circumstances as the future unfolds. [34].

\subsection{Design for flexibility}

What Fricke and Schultz consider the next measure of stage setup is that it consolidates versatility. [22]. It very well may be contended that flexibility isn't only an open door for included worth or an invite symptom of a decent structure; in an aggressive domain, it is a plan necessity. Wang and de Neufville [67], Wang [66] and de Neufville [47] based on the idea and hypothesis of real options to recognize managerial flexibility that is emergent or circumstantial in the advancement and activity of a framework, and flexibility that must be envisioned, structured and built into frameworks.

On one hand, stage structure and standardization gives off an impression of being an extraordinary wellspring of significant worth. On the other, adaptable structure was exhibited to be just about a need in an unsure focused condition. What is the degree to which these criteria compete and by what form can they be central, in particular to the development of large-scale frameworks? These can be linked because standardization will improve critical versatility by enabling developers to organize and develop easier and more flexible systems, use existing skills to enter new activities and markets effectively, or even quitting high-rescue projects (because structures and sections can be used in various enterprises).

\section{Literature Review}

The development of stage-based element families involves standardization of similar segments and their interfaces with non-standardized segments. On the whole, stage technique includes all the building and board choices on how, when and what object variations and stages to be produced. At an unprecedented point, the process involves standardization of the majority of the segments of the item: the paradigm established by Henry Ford. On the other side, the customization of an object may rely on the customization of the whole of its pieces, which is the condition of essential, rather than calculated, objects [34].

The halfway structure is driven by the fractional modification of segments within a set of products; the non-modified portion is the stage for the family of things. Firms, particularly in the car business, are pushing the field in the rising of surprisingly reddish products, based on the exceptionally small number of item families. On the upside, stage configuration prompts basic assembling forms, innovation, information move over the association and its store network and decrease in assembling resources and tooling. From an authoritative perspective, an item stage empowers the firm to have a cross-utilitarian group inside item improvement; this thusly makes item and procedure combination a lot simpler and less unsafe. Then again, putting together a scope of items with respect to a stage can have impediments. For the time being, the underlying expense of building up a stage is frequently a lot higher than the expense of planning and creating a solitary item [20]. This cost increment is joined by an expansion in specialized dangers: since numerous item variations depend on a similar stage, the probability and effect of specialized mistakes in the structure of the stage is bigger.

In order to address this examination, the drafting of the stage plan has encountered two basic difficulties: right off the bat, the division of the unforeseeable structure into stages and the obvious 
evidence of the standard module (step) in the element unit. The second area of research was to determine the benefits of the stage system [34].

\subsection{Platform selection and evaluation}

For some systems, the judgment on stage structures or procedures between variations is straightforward: it may be instinctive or develop normally from current variations. Potential stages are those frameworks that go about as "transports" here and there [70], or those that give interfaces between other, redid frameworks. For sure, most item stages are chosen naturally, both by and by and in the scholarly writing. In any case, the intentional recognizable proof of stages is increasingly troublesome in arrange like frameworks or frameworks in which stages are involved subsystems and parts from different degrees of framework collection.

Existing methods to assess the stage could be handled in two different ways. One approach was to limit the size of the consolidated room with the use of semi-subjective methods and, ultimately, to enable the system supervisors to choose the correct parceling. One approach was to search for optimal parcels of system variables in updated and structured modules using streamlining heuristics [34].

Enhanced hunting method includes illustrating the net benefit (or cost) as part of the scheme characteristics of variations, at that point amplifying the profit (or reducing the cost) by adjusting the structural factors that affect the step. For starters, Fujita, et al. outlines the problem of stage choice as a 0-1 number system together with the streamlining issue of stage and variety [23]. In the same manner, Simpson and D'Souza take care of the issue of stage ID and streamlining in a solitary stage using a multi-objective genetic assessment, where part of the genome in the measurement "decides" the variables are part of the stage and initiates correct limitations [13].

This methodology requires a designing framework model just as a model of the advantages of every stage technique. At that point, incorporating the stage recognizable proof issue with the item family streamlining issue is computationally serious however genuinely straight-forward. In this way, the pertinence of these calculations is restricted by computational capacities

The alternative approach relies on "manual" visible evidence of stage segments in an object family by sorting the variables and pieces into modules and then investigating successful options of stage modules. The rule is that the architecture of the stage modules must be "robust" to the changes in particular between the variants of the object, while the changed modules must be "flexible" [54].

A similar line of research has tried to determine the whole stage of the method, i.e. the whole set-up of the system and the modifications, as far as the costs and benefits of constructing a stage are concerned. These are then integrated in the numerical model, e.g. the net present value (NPV) of the stage strategy for market systems and products. Typically, the NPV is calculated to accept the usual estimate of uncertain future strategy pre-requisites, progress, and economic situations for the subsequent variations. Notwithstanding, in light of the fact that (1) the estimation of a stage system doesn't depend directly on these vulnerabilities, and (2) the arrangement of variations later on isn't compulsory, yet in the watchfulness of the creating association, these uncertainties must be considered explicitly for the plan of the underlying stage.

\subsection{Flexibility and real options}

In a restricted sense, the real options writing expands on a similarity among tasks and venture openings, and plain vanilla financial options [3]. The last are contracts empowering the holder of 
the option to purchase (or sell) a security at a predetermined exercise cost later on, inside a predecided time window. The holder's right (without the commitment) and the guarantor's commitment to satisfy the holder's correct, gives a choice agreement its incentive at the time it is composed. Computing this worth was an unsolved issue in financial matters since the mid twentieth century. The arrangement came in shut structure with the Black-Scholes recipe [41], which empowered the estimation of the estimation of a European call choice on a non-profit paying stock. Several productions since have utilized the equivalent or comparable numerical development as Black and Scholes did, to esteem options contracts with an assortment of attributes. Steward Myers initially broadened the idea of an option to circumstances where no conventional agreement is composed; rather, the "holder" of the "option" has the right (without the commitment) to induce a particular activity inside a time period later on; see Myers and Brealey [8] and Dixit and Pindyk [18].

A considerable lot of the options that contain an undertaking's administrative adaptability are accessible at any rate: no proactive activities are expected to "purchase" these alternatives and empower this adaptability. For instance, the adaptability to forsake an undertaking during its improvement exists more often than not; no unique activity heretofore is expected to acquire it. These options are significant and may have extraordinary commitment to a venture's worth.

Notwithstanding this, decisions remain open to the company because they have already been created in the strategy and on the board of the undertaking; this specific alternatives are the focal point of this project. Because these choices include a purposeful organization and layout, they can be defined as' in' frameworks; see de Neufville [15] and Wang and de Neufville [67]. These alternatives are periodically associated with actions that can be reached by the company for potential projects, which can also be defined with organizational versatility, the proportion of fixed to rising expenses, adjustments in the size ongoing or the mix of choices produced during the development and function of the undertaking.

Notwithstanding the fact that this versatility is technically understood to architects and designers, constructing structures are customarily meant for set details. This training lasts in every case, where confusion about the progress or working conditions of the system is recognised, inferring that versatility might be necessary. Once again, the concept of deliberately designing structures with the goal of encouraging the creation of resilience.

\subsection{Option valuation}

In the initial depictions of the options principle, the (normal point of reference) continuous path to time is typically shown after increasingly instinctive binomial trees. The reason is that these approaches need some knowledge on stochastic analytics, which is weird and challenging to follow. The introduction ends with Cox, et al.'s outstanding binomial program [12] (CRR), this is common for reading content on account; e.g. Myers and Brealey [8]. Extensions of the CRR strategy can be contained in Hull [30]. An alternate binomial model is then demonstrated by Arnold and Crack [4], which relies on the discretization of the first valid time scale of Black and Scholes. Gradually, reproduction techniques for estimating options are given below.

External simulation pricing genuinely incorporates the risk-impartial valuation result: the process requires the era of thousands of research methods for the development of the secret capital as if the risk-free rate of return had been obtained. Evaluating American reproductive options is getting more and more controversial. The reason is that the decision to train early (i.e. before lapse) relies on comparing the calculation of accelerated exercise with the usual calculation of the option one looks forward to [34]. In this case, the count must be periodic, running in reverse in the same manner as in the cross-section approach; however, the re-enactment of the routes persists, which 
ensures that leisure methods do not provide timely details on the limiting calculation of the essential resource expected later. There are various classifications of approaches that aim to overcome this problem; for delegated techniques, see, for example, Longstaff and Schwartz [39], Andersen [39], and Ibanez and Zapatero [32]. The methodology used in this paper to test alternatives relies on the stratified state set and the measurements produced by Tilley [64], Barraquand and Martineau [5], and Rayman and Zwecher [50].

\subsection{Global chains and real options analysis}

In global chains, supply chain components are not located in one country and are scattered in other countries. As is clear from the foregoing discussions, these chains provide many options with organizational managers and decision makers whose analysis is particularly important in large-scale engineering programs and projects. There have been numerous studies on global chains that table 1 summarizes and classifies important articles in this field. 
Table 1. Classification of important articles in global supply chains

\begin{tabular}{|c|c|c|c|c|c|c|c|c|c|c|c|c|c|c|c|c|c|c|c|c|c|c|c|}
\hline \multirow[b]{2}{*}{ Paper } & \multirow{2}{*}{ 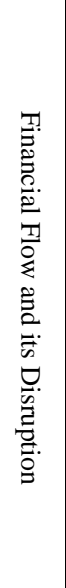 } & \multicolumn{8}{|c|}{ 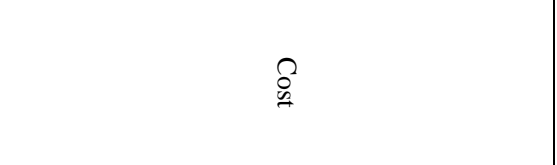 } & \multirow[b]{2}{*}{$\begin{array}{l}\vec{\Xi} \\
\stackrel{0}{\Xi}\end{array}$} & \multirow[b]{2}{*}{$\begin{array}{l}n \\
0 \\
\vdots \\
\vdots \\
0 \\
0 \\
0 \\
0 \\
0\end{array}$} & \multicolumn{4}{|c|}{ 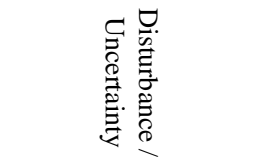 } & \multicolumn{4}{|c|}{ 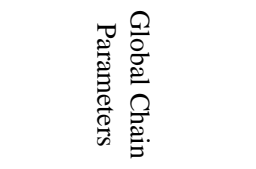 } & \multirow{2}{*}{ 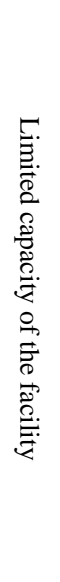 } & \multirow[b]{2}{*}{ 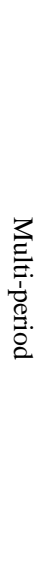 } & \multirow[b]{2}{*}{ 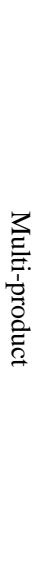 } & \multirow[b]{2}{*}{ 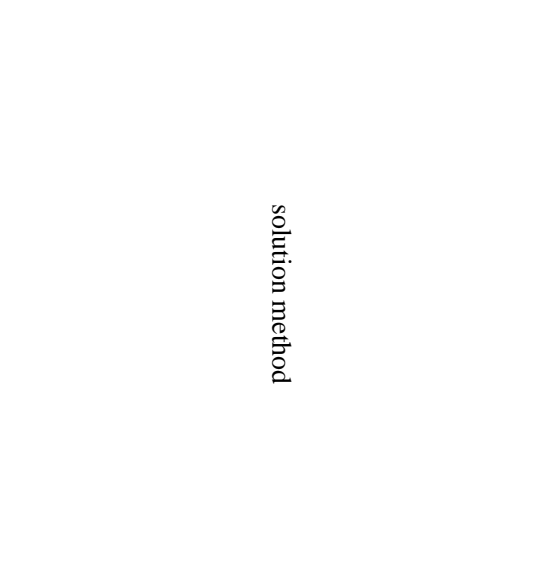 } \\
\hline & & 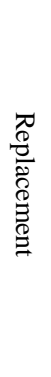 & 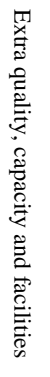 & 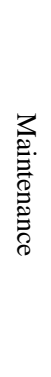 & 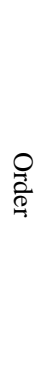 & 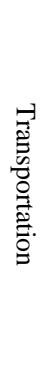 & 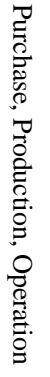 & 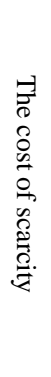 & 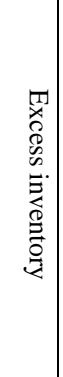 & & & $\frac{n}{\tilde{\sigma}}$ & 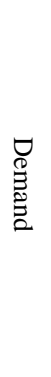 & 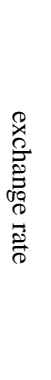 & ْి & 急 & 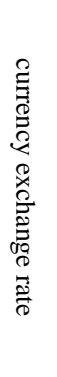 & 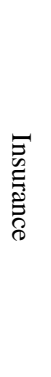 & $\overrightarrow{\vec{E}}$ & & & & \\
\hline Recent paper & $*$ & & & * & & $*$ & $*$ & & & $*$ & & $*$ & $*$ & $*$ & & $*$ & $*$ & $*$ & $*$ & $*$ & $*$ & $*$ & Robust possibilistic programming \\
\hline $\begin{array}{c}\text { Yun et al. } \\
{\left[\mathrm{V}^{\prime}\right]}\end{array}$ & & $*$ & & $*$ & & * & $*$ & & $*$ & & $*$ & & $*$ & & & * & & $*$ & $*$ & & * & $*$ & Pareto optimal solution, hybrid genetic algorithm \\
\hline $\begin{array}{c}\text { de Castro Vivas et al. } \\
{\left[{ }^{\leftarrow}\right]}\end{array}$ & $*$ & & * & & $*$ & $*$ & $*$ & & & $*$ & $*$ & $*$ & $*$ & & $*$ & $*$ & & * & $*$ & & * & * & $\begin{array}{l}\text { Sustainable supply chain, AHP, Goal } \\
\text { programming, PROMETHEE }\end{array}$ \\
\hline $\begin{array}{c}\text { Fazli-Khalaf et al. } \\
{\left[r^{\prime}\right]}\end{array}$ & & $*$ & $*$ & * & & & & * & & $*$ & & * & $*$ & & $*$ & & & $*$ & & & $*$ & * & Robust possibilistic programming \\
\hline $\begin{array}{c}\text { Khalilpourazari et al. } \\
{\left[r^{\circ}\right]}\end{array}$ & & $*$ & & & $*$ & $*$ & & & $*$ & $*$ & & $*$ & $*$ & & & & & $*$ & & & $*$ & * & $\begin{array}{c}\text { robust possibilistic programming, meta-heuristic } \\
\text { algorithms }\end{array}$ \\
\hline $\begin{array}{c}\text { Sawik } \\
{\left[\Delta{ }^{\top}\right]}\end{array}$ & $*$ & $*$ & $*$ & & & $*$ & & $*$ & & $*$ & & $*$ & $*$ & & $*$ & & $*$ & & & $*$ & $*$ & $*$ & $\begin{array}{l}\text { portfolio approach, stochastic programming, } \\
\text { mixed integer linear programming }\end{array}$ \\
\hline $\begin{array}{c}\text { Thorlakson et al. } \\
{\left[{ }^{4 \Gamma}\right]}\end{array}$ & $*$ & $*$ & & $*$ & $*$ & $*$ & & $*$ & & $*$ & & $*$ & $*$ & & $*$ & & & & & & $*$ & * & $\begin{array}{l}\text { large-scale empirical analysis of corporate } \\
\text { sustainable-sourcing practices }\end{array}$ \\
\hline $\begin{array}{c}\text { Song and Gao } \\
{[\Delta \wedge]}\end{array}$ & & $*$ & & $*$ & & & $*$ & $*$ & & & $*$ & $*$ & $*$ & & $*$ & $*$ & & & $*$ & & $*$ & * & $\begin{array}{c}\text { Game model } \\
\text { Green sensitive } \\
\end{array}$ \\
\hline $\begin{array}{c}\text { Kim and Chai } \\
{\left[{ }^{\top \vee}\right]}\end{array}$ & & $*$ & & & & $*$ & & $*$ & & $*$ & & & $*$ & & & & $*$ & & & $*$ & & $*$ & Diffusion of innovation theory (DOI) \\
\hline $\begin{array}{l}\text { Hasani and } \\
\text { Khosrojerdi }\end{array}$ & $*$ & & & $*$ & & $*$ & $*$ & & & & $*$ & $*$ & $*$ & & $*$ & & & & & & $*$ & $*$ & mixed-integer, non-linear model \\
\hline $\begin{array}{c}\text { Hasani et al. } \\
{[r v]}\end{array}$ & $*$ & & $*$ & & $*$ & & & * & & $*$ & & & & $*$ & $*$ & & & & & $*$ & $*$ & $*$ & Precise and heuristic method \\
\hline Sun [61] & & & & & & * & $*$ & & & & & & & & & & & & & & & $*$ & Analytical Solution Method \\
\hline $\begin{array}{c}\text { Hushmandi } \\
{[31]}\end{array}$ & & & $*$ & $*$ & $*$ & & $*$ & $*$ & & & & & & & & & & & & $*$ & & & Network Analysis and Genetic Algorithm \\
\hline Liu and Papageorgiou & & $*$ & & * & & & $*$ & & & & & & & $*$ & & & & & & $*$ & $*$ & $*$ & e-constraint method \\
\hline
\end{tabular}




\begin{tabular}{|c|c|c|c|c|c|c|c|c|c|c|c|c|c|c|c|c|c|c|c|c|c|}
\hline Paper & 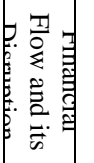 & \multicolumn{7}{|c|}{ 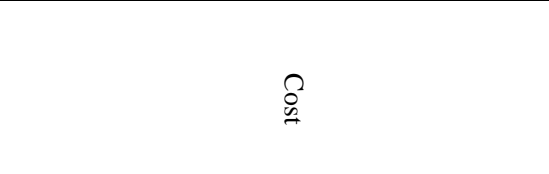 } & 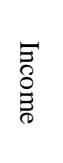 & 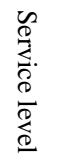 & \multicolumn{3}{|c|}{ 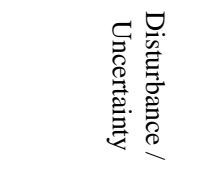 } & \multicolumn{4}{|c|}{ 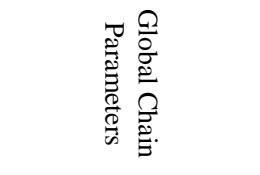 } & 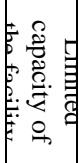 & 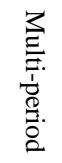 & 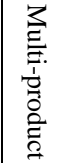 & 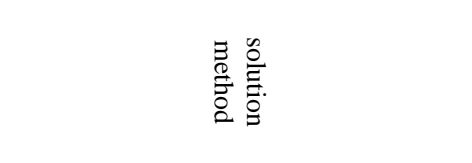 \\
\hline [38] & & & & & & & & & & & & & & & & & & & & & \\
\hline Singh et al. [56] & & * & & & & * & * & * & & & & & $*$ & & $*$ & & & $*$ & & & Integer programming/modeling method \\
\hline Sousa et al. [60] & & & * & & $*$ & * & & & $*$ & & & & & & & & & & * & * & Analytical Algorithm \\
\hline Acar at al. [1] & & & * & & $*$ & * & $*$ & & & & & $*$ & & $*$ & & & & & * & * & Complex integer programming \\
\hline Perron et al. [49] & & & $*$ & & $*$ & * & & & & & & & & & & & $*$ & * & & * & Precise and heuristic method \\
\hline You et al. [69] & & & * & & $*$ & & $*$ & & & & & $*$ & & & $*$ & & & & * & & L-shaped method \\
\hline Goh et al. [24] & & & & & $*$ & * & & & & & & $*$ & * & & $*$ & & & & & & Random planning \\
\hline $\begin{array}{l}\text { ElMaraghy and } \\
\text { Mahmoudi } \\
{\left[1^{9}\right]}\end{array}$ & & & * & $*$ & & * & * & & & & * & $*$ & & & & & & & & * & integer linear decision support model \\
\hline $\begin{array}{l}\text { Narasimhan and } \\
\text { Mahapatra } \\
{\left[{ }^{+4}\right]}\end{array}$ & & $*$ & & & & * & & & $*$ & & & & & $*$ & & $*$ & * & & & & Analytical Solution Method \\
\hline Nagurney et al. [45] & & & & & $*$ & * & & & $*$ & & & & $*$ & & $*$ & & & & & & Dynamic programming \\
\hline $\begin{array}{l}\text { Hadjinicola and Kumar } \\
\text { [26] }\end{array}$ & & & $*$ & & $*$ & & & & $*$ & & & & $*$ & & & & & & & & Mathematical modeling \\
\hline $\begin{array}{c}\text { Vidal and } \\
\text { Goetschalckx [65] }\end{array}$ & & & $*$ & & * & & & & $*$ & & & & & $*$ & $*$ & & $*$ & & & & Metaheuristic \\
\hline
\end{tabular}


As is well known in research, the issue of impairment and uncertainty and its effect on the network has not received much attention. The flow of money in the global supply chain has been neglected and all the parameters of the global supply chain have not been taken into account unanimously.

The current research innovations can be summarized in three parts: global supply chain modeling in disruptive conditions- where the selected strategy is transfer through brokers- given most of the parameters in the global supply chain (exchange rate, insurance, customs clearance, tax). Modeling physical and financial flows and disrupting these two flows simultaneously, using robust possibility programming in combination with options theory approach to problem modeling and calculating the value of real options that has benefits

The reason for using this type of planning compared to other methods is:

- An approach to dealing with uncertainty in the problem is beyond a simple solution which with the two indicators of robustness of optimization and robustness of feasibility does not have many problems in other approaches;

- A risk-averse approach that is appropriate for embedded disorder situations that are complex and highly ambiguous;

- On the other hand, this approach is good for long-term planning, and with many leading-edge futures, it performs well with the least fluctuations and leaves the least regret.

\section{Flexibility valuation in large-scale engineering programs}

The recognizable proof of stages is increasingly troublesome in organize like frameworks or frameworks in which stages are contained subsystems and parts from different degrees of framework accumulation.

Step-recognizable proof is equally difficult in large and complicated systems, because the scale of the collective space of step procedures is $2^{n}$, where $\mathrm{n}$ is the quantity of unmistakable segments or modules in the framework [55]. The solutions in this section are used to the total size of this room by addressing the physical and structural imperatives posed by the architecture of the modules and the functional specifications of the structure. With regards to structuring adaptability in projects of various huge scale improvements, the system presented in this section is utilized for screening elective standardization methodologies that might be ideally executed later on.

The theory used to determine adaptability is actual choices. The process starts with the monetary financial implications published in the 1970's, and then, the bulk of scholarly attempts were made to "apply" it to the field of building valuation. These activities have centered on qualitative studies, which demonstrate the concept and usage of specific alternatives in the analysis and enhancement of system architecture. Applications involve staggered submission of communication satellite star clusters under requirement uncertainty [17]; option of segment mutual feature between two aircraft with a related family [40]; building plan under lease and susceptibility to space use; e.g. see Zhao and Tseng [72], Kalligeros and de Weck [33], Greden and Glicksman [25] and de Neufville et al. [16]. Notwithstanding these actions, the theories and the formal methods had virtually no foundation among the experts.

It is believed that the modest admission of the actual options protocol may be attributed to two basic factors. Right off the start, much of the architecture writing on adaptability and actual alternatives does not seem to be compatible with simple concepts and a single view method. Flexibility is commonly conceptualized as a set of specific choices (i.e. a privilege, but not a promise to alter, expand, contract or otherwise advance the framework) and this has created a fundamentally important fascination for engineers. To be sure, the dedication of a portion of these qualitative inquiries is to conceptualize the actual choices pertaining to the problem of the house, without trying to provide a detailed analysis of the choice. Again, none of these implementations offers a basic, instinctive and consistent method (or "language") for explaining and offering consistency in the construction program. [34].

The second goal behind the modest intrusion of specific alternatives into building practice is known to be to push the "unaltered" and constructive monetary theory to the "development level" of the building system. During a moment where an in-depth option of valuation is being pursued in the development of projects, it 
is, for the most part, confronted with imaginary blunders, common sense obstacles in the specification, and rational conflicts that satisfy neither designers nor fund arranging crowds.

A practical approach for versatility assessment in the management architecture environment is essential to this research. In the off risk that the professional may not be able to determine the adaptability potential of institutionalization (or any other technical development, as far as this is concerned) at this stage, they will not have a straightforward and quantifiable way to plan for it. For this form of logic, a new specific option valuation mechanism is set up, which overcomes these barriers to the limited mystery of the concept of nature. The new methodology is similar to zero of the existing "sensitivity review" rehearsals of the framework evaluation.

A novel re-enactment-based theory is seen in the next segment for the organization of these requirements and the assessment of elective system choices. The estimate depends on the re-enactment and stratified state selection procedures developed in the 1990s by Tilley, Barraquand and Martineau [5], Raymar and Zwecher [50], Broadie and Detemple [9], Broadie and Glasserman [10] and others.

\subsection{Research methodology}

The current research is an applied research and the method of gathering information is based on a case study. The process of collecting information for modeling is as follows:

1. Interviews with the manager of a business complex provide information necessary to understand the components of the supply chain, their relationship, how sanctions affect the company, and the strategies adopted under sanctions.

2. The documentation and reports have been studied and the information provided has been completed. The result of this and the previous step has been to derive the general framework and model assumptions.

3. Mathematical modeling is performed and the necessary numerical data is obtained from the set. The approach used in this study is "Operations Research". This method is one of the "hard systemic thinking" approaches.

Linear programming is used to analyze the data and the robust possibility programming in combination with the real options theory approach is used to deal with the uncertainty of the problem and it has been modeled in GAMS optimization software.

There are two particular branches in the Operations Research (OR) writing engaging for the consideration of managerial flexibility in the arranging of firms' tasks under vulnerability (for example [44, 51]). For example, real options analysis (ROA), for instance of Hard OR strategy, grasps standards of stochastic dynamic programming and unexpected cases examination to assess firms' speculation portfolios when looked with noteworthy degrees of uncertainty $[57,59]$. Soft OR scholars on the other hand, like to receive an alternate methodology towards ventures arranging by first revealing insight into the human, social and political components influencing system plan and strategy making, and second recognizing and organizing, with at least or no evaluation, the "complex and messy" issues looked by decisionmakers when undertaking responsibility (see $[2,52]$ ), before third conceivably moving to a "harder" formalization of their examination (for example [43]). In spite of the obvious dissimilarity between the two methodologies, for example ROA and vigor investigation, as far as detail and execution, it is unseemly to dismiss their analogies and down to earth complementarities. The parallel spotlight on flexibility and successive arranging, just as alternatives and irreversibility, irrefutably alludes to binding the two systems to one. Here, we build up a choice supporting structure (for example $[6,36]$ ) to survey the power or productivity of real options in associations when looked with different degrees of uncertainty. Planned to be of participatory nature, the featured methodology likewise sets the justification for increasingly functional methods for organizing real option standards in firms' corporate procedures and undertaking structures.

In studies where uncertainty is related to the lack of data or knowledge about the exact value of the input parameters of the problem, possibility programming is used. Nonlinear parameters also have a trapezoidal distribution. But regarding the reason for the preference of robust possibility programming over possibility programming, It must be acknowledged that the results and decisions made by the possibility programming method are not always reliable. This is due to the need for possible deviations from the mean value of the 
objective function as well as the exceedance of the constraints and the consequent non-saturation of the constraints that have uncertain parameters. In addition, the level of assurance of limitations with nondeterministic parameters must be specified by trial and error and passive interactions, which require timeconsuming experiments, It also ensures that the selected confidence levels are not the same as the optimal values. The robust possibility programming model is outlined below. $\alpha$ is the equilibrium averages show the results obtained here from the parametric state and become a decision variable.

In light of standards of robustness analysis, we show how choice helping can encourage support in ventures setting and accomplish successful basic leadership using real options thinking. We contend that strength heuristics created in before studies can be handy intermediaries for real options execution, henceforth markers of productive adaptable arranging. At the end of the day, we features the procedural mechanics of power investigation as an observing apparatus for real options arranging and apply standards of strength examination to the real options paradigm and the other way around.

As for the need to combine a robust possibility programming approach with an authority theory approach, since the authority approach has the potential to measure the value embedded in uncertainty decisions, it seems likely to combine it with robust possibility programming. Much of the potential for this approach in analyzing the uncertainties in the supply chain is enhanced. In fact, we use a robust possibility programming approach to calculate the value of the discretion lies at the heart of the various decisions that managers make to address the uncertainties in the supply chain.

Much research has been done so far on the application of the real options method to justify the uncertainties in the various supply chains, but in most of them, initial investment has been considered. Given that the supply chain turnover period lasts several months and the economic conditions change at different times, it is necessary to invest in each supply chain, taking into account the options and assessing existing uncertainties and balancing the risk and the resulting benefits. Special emphasis is also placed on providing a real options-based approach to evaluating possible investment options in different supply chains. Using the proposed approach, management can evaluate opportunities by considering the uncertainty and flexibility of options and make the best decision based on the specific risks of the chain.

Different methods have been proposed to calculate the value of the option and different computational techniques have been proposed for each method. The two main methods for calculating the value of option in managers' decisions to deal with uncertainty are partial differential equations (PDE) and simulation methods that each method in turn consists of different solution approaches. In this paper, a robust possibility programming approach is used to calculate the value of optoins.

\subsection{Mathematical modeling of the problem}

It section explores and discusses the possible fulfillment of these promises to promote concrete strategies for considering and evaluating the development schedule. The debate starts with the versatility of the system in explaining the different problems of strategy and development. First, a novel empirical approximation for the estimation of such options is attempted against the distributed tests. At the end of the day, the drawbacks of the current concept choice valuation strategy are discussed from a financial point of view [34].

The assumptions underlying the model are as follows. The capacity of the facility is limited. Suppliers are limited in the amount of material available. The logistics network is multi item and multi product. It is possible to estimate customer demand from multiple production centers. Customer demand must be satisfied at the end of each time period. Raw material purchased from suppliers has a shelf life and must be converted into a final product over its lifetime. The finished product produced at the production center also has a specific life span that must be achieved by the consumer in the same period. The system for delivering goods to the customer and using the raw material purchased is FIFO. Exchange rate and customer demand parameters are uncertain. The purpose of the current modeling is to minimize costs during the provision as well as maximizing the value of the option lies in the managers' decision. The following will describe the variables, constraints, and objective function.

The conditions of exposure to sanctions, or more precisely, uncertainties are modeled with two parameters, $h_{j s}, a_{j s}$. If scenario is terminated due to the embargo on communication with supplier $j$ in 
scenario $s, h_{j s}$ value will be 1 , otherwise it will be zero. If due to the embargo, the cash flow with the supplier $j$ in the scenario $s$ is through intermediaries, $a_{j s}$ value will be 1 and otherwise zero. The objective function seeks to manage and reduce the costs of financing as well as maximizing the options value lies in the decision of managers. $p_{s}$ is the probability of each scenario occurring, $C_{t}$ is the sum of the cost of goods sold at the end of period $t, i o_{p o}^{t, s}$ is the product inventory at the production center at the end of the period in each scenario, $\tau_{p o i}^{t, s}$ is the amount of material shipped and $O\left(\bar{s}_{t}^{m}\right)=e^{-r_{f} \delta t}\left[\underset{m}{E}\left[F\left(\bar{s}_{t+\delta t}\right)-\bar{s}_{t}^{m}\left(e^{r_{s} \delta t}-e^{r_{f} \delta t}\right) \frac{\underset{m}{\sigma}\left[F\left(\bar{s}_{t+\delta t}\right)\right]}{\underset{m}{\sigma}\left[\bar{s}_{t+\delta t}\right]}\right]\right]$ is equal to the amount of option. The formulation of the extent of the option and how to obtain is discussed in full in the appendix. $r_{e, o}^{t, s}$ variable is the raw material inventory at the production center at the end of the period in each scenario. $s r_{e j o}^{t, s}$ is the amount of raw material is shipped. The developed model is single-purpose and aims at reducing overall system costs, as well as maximizing the value of the buy or sell option. Constraints also fall into two general categories. The first category is the physical flow constraints and the second is the flow constraints.

$$
\begin{aligned}
& \min f=\sum_{s \in S} p_{s} * \sum_{t} C_{t}-O\left(\bar{s}_{t}^{m}\right) \\
& O\left(\bar{s}_{t}^{m}\right)=e^{-r_{f} \delta t}\left[\underset{m}{E[}\left[F\left(\bar{s}_{t+\delta t}\right)-\bar{s}_{t}^{m}\left(e^{r_{s} \delta t}-e^{r_{f} \delta t}\right) \frac{\underset{m}{\sigma}\left[F\left(\bar{s}_{t+\delta t}\right)\right]}{\underset{m}{\sigma}\left[\bar{s}_{t+\delta t}\right]}\right]\right]
\end{aligned}
$$

s.t.:

$\sum_{s \in S} p_{s}=1$

$\forall e, o, t, s \quad r_{e, o}^{t, s}=r_{e, o}^{t-1, s}+\sum_{j} s r_{e j o}^{t, s}\left(1-h_{j s}\right)-\sum_{p} \pi_{p e} \cdot \zeta_{p o}^{t, s}$

$\forall e, j, t, s \quad \sum_{o} s r_{e j o}^{t, s} \leq U_{e j}^{t, s}$

$\forall p, o, t, s \quad \omega_{p o}^{t, s}=\omega_{p o}^{t-1, s}+\zeta_{p o}^{t, s}-\sum_{i} \tau_{p o i}^{t, s}$

$\forall p, o, t, s \quad \gamma_{p o}^{t} \leq \zeta_{p o}^{t, s} \leq \Gamma_{p o}^{t}$

$\forall i, p, t, s \quad \sum_{o} \tau_{p o i}^{t, s} \geq \hat{q}_{i p}^{t}$

$\forall e, o, s, t \neq T \quad \sum_{t^{\prime}=1}^{\min \left(t+E x_{e}, T\right)} \sum_{p} \pi_{p e} \cdot \zeta_{p o}^{t^{\prime}, s}-\sum_{t^{\prime}=1}^{t} \sum_{j} s r_{e j o}^{t^{\prime}, s}\left(1-h_{j s}\right) \geq 0$

$\forall p, o, s, t \neq T, u_{p}>1 \quad \sum_{t^{\prime}=1}^{\min \left(t+L_{e}-u_{p}, T\right)} \sum_{p} \tau_{p o i}^{t^{\prime}, s}-\sum_{t^{\prime}=1}^{t} \zeta_{p o}^{t^{\prime}, s} \geq 0$

$\forall o, t, s \quad \sum_{j} \alpha_{j, o, s, t} \leq U s_{o}$ 


$$
\begin{aligned}
& \forall i, t, s \quad \sum_{o} \beta_{o, i, t, s} \leq U p_{i} \\
& \forall e, j, o, t, s \quad s r_{e, j, o, t, s} \leq M_{1} * \alpha_{j, o, t, s} \\
& \forall p, o, i, t, s \quad \tau_{p, o, i, t, s} \leq M_{2} * \beta_{o, i, t, s}
\end{aligned}
$$

$$
\text { parameters } \geq 0
$$

Constraint 3 is related to the total weight of the scenarios that must be equal to one. Constraint 4 indicates the amount of raw material available at the production center $o$ in each period and each scenario that is transferred from each period to the next. $\zeta_{p o}^{t, s}$ is the quantity of product and $\pi_{p e}$ is the coefficient of use of each raw material for each product. Constraint 5 applies to the capacity of each supplier to supply each raw material in different periods and scenarios. $U_{e j}^{t, s}$ indicates the maximum amount the supplier is able to supply from the raw material in each period and in each scenario. Constraint 6 resulting from the commodity $p$ at the end of the period $t$ in the production center $o$, under each scenario, is transmitted from each period to a subsequent period. Each production center has a minimum and maximum production capacity for each product in each period, ie, $\gamma_{p o}^{t}, \Gamma_{p o}^{t}$ and is indicated in constraint 7. The total of goods shipped in each period from production centers to customers must be equal to their demand as shown in constraint 8. $\hat{q}_{i p}^{t}$ shows customer demand for each product at the end of each period. Constraint 9 is written to prevent corruption of raw material purchased by the supplier. $l_{e}$ shows the shelf life of any raw material. Constraint 10 indicates that manufactured goods must be consumable at least until the period prior to the expiry of their period of use. $L_{p}$ shows the shelf life of each finished product. Constraint 11 indicates that a maximum of several currents between each generator and supplier can be switched off. If in the period $t$ and scenario $s$ the flow from supplier $j$ to producer $o$ is set, the variable $\alpha_{j, o, t, s}$ gets 1 and otherwise $0 . U s_{o}$ shows the maximum number of suppliers per production center. Constraint 12 also indicates this issue between customers and manufacturers, so that each customer's demand can be met by multiple manufacturers. If in period $t$ and scenario $s$ the flow from producer $o$ to customer $i$ is made, the variable $\beta_{o, i, t, s}$ gets 1 and otherwise gets $0 . U p_{i}$ shows the maximum number of production centers per customer. Constraints 13 and 14 show the relationship between the zero and one variable allocation and the flow variables that if the values of zero and one variables are taken, the flow variables are activated. $\mathrm{M}_{1}$ and $\mathrm{M}_{2}$ are two very large numbers. A robust possibility programming model in combination with options theory is outlined below:

$$
\begin{aligned}
& \min f=\sum_{s \in S} w a_{s} * \sum_{t} \operatorname{cog}_{t}= \\
& \sum_{s \in S} w a_{s} *\left(\sum_{p, o} q p_{p o}^{t, s} \cdot p \cos t_{p o}^{t}+\sum_{p, o, i} t r o i_{p o i}^{t} \cdot q o_{p o i}^{t, s}+\sum_{e, j, o}\left(t r j o_{e j o}^{t} * \frac{e x_{1}+e x_{2}+e x_{3}+e x_{4}}{4}\right) \cdot q j_{e j o}^{t, s}+\right. \\
& \sum_{p, o} h o_{o}^{p} \cdot \frac{i o_{p o}^{t, s}+i o_{p o}^{t-1, s}}{2}+\sum_{e, o} h e_{o}^{e} \cdot \frac{i m_{e, o}^{t, s}+i m_{e, o}^{t-1, s}}{2}+\left(1+\alpha l_{t}\right)+ \\
& \left(t i i_{t}+n a_{t}+\alpha l_{t}\right) *\left(\sum_{e, j} \frac{e x_{1}+e x_{2}+e x_{3}+e x_{4}}{4} \cdot p p r i c e_{e, j}^{t} \cdot \sum_{o} q j_{e j o}^{t, s}+\sum_{e} b i_{e}^{t} \cdot \frac{e x_{1}+e x_{2}+e x_{3}+e x_{4}}{4} \cdot \sum_{j, o} q j_{e j o}^{t, s}\right)+
\end{aligned}
$$




$$
\begin{aligned}
& \sum_{e, j, o}\left(1-h_{j s}\right) \cdot a_{j s} \cdot\left(s \cos t_{e j o}^{t}+b \cos t_{e j o}^{t}\right) \cdot q j_{e j o}^{t, s}+\varphi\left(\sum _ { s \in S } w a _ { s } * \left(\sum_{p, o} q p_{p o}^{t, s} \cdot p \cos t_{p o}^{t}+\sum_{p, o, i} t r o i_{p o i}^{t} \cdot q o_{p o i}^{t, s}+\right.\right. \\
& \left.\sum_{e, j, o}\left(t r j o_{e j o}^{t} * e x_{4}\right) \cdot q j_{e j o}^{t, s}\right)+\sum_{p, o} h o_{o}^{p} \cdot \frac{i o_{p o}^{t, s}+i o_{p o}^{t-1, s}}{2}+\sum_{e, o} h e_{o}^{e} \cdot \frac{i m_{e, o}^{t, s}+i m_{e, o}^{t-1, s}}{2}+\left(1+\alpha l_{t}\right)+\left(t i i_{t}+n a_{t}+\alpha l_{t}\right) \\
& *\left(\sum_{e, j} e x_{4} \cdot p p r i c e_{e j}^{t} \cdot \sum_{o} q j_{e j o}^{t, s}+\sum_{e} b i_{e}^{t} \cdot e x_{4} \cdot \sum_{j, o} q j_{e j o}^{t, s}\right) \\
& +\sum_{e, j, o}\left(1-h_{j s}\right) \cdot a_{j s} \cdot\left(s \cos t_{e j o}^{t}+b \cos t_{e j o}^{t}\right) \cdot q j_{e j o}^{t, s} \\
& -\sum_{s \in S} w a_{s} *\left(\sum_{p, o} q p_{p o}^{t, s} \cdot p \cos t_{p o}^{t}+\sum_{p, o, t} t r o i_{p o i}^{t} \cdot q o_{p o i}^{t, s}+\sum_{e, j, o}\left(t r j o_{e j o}^{t} * \frac{e x_{1}+e x_{2}+e x_{3}+e x_{4}}{4}\right) \cdot q j_{e j o}^{t, s} \sum_{p, o} h o_{o}^{p} \cdot \frac{i o_{p o}^{t, s}+i o_{p o}^{t-1, s}}{2}\right. \\
& +\left(1+\alpha l_{t}\right)+\left(t i i_{t}+n a_{t}+\alpha l_{t}\right) *\left(\sum_{e, j} \frac{e x_{1}+e x_{2}+e x_{3}+e x_{4}}{4} \cdot p p r i c e_{e, j}^{t} \cdot \sum_{o} q j_{e j o}^{t, s}+\sum_{e} b i_{e}^{t} \cdot \frac{e x_{1}+e x_{2}+e x_{3}+e x_{4}}{4} \cdot \sum_{j, o} q j_{e j o}^{t, s}+\right. \\
& \left.\left.\sum_{e, j, o}\left(1-h_{j s}\right) \cdot a_{j s} \cdot\left(s \cos t_{e j o}^{t}+b \cos t_{e j o}^{t}\right) \cdot q j_{e j o}^{t, s}\right)\right)+\delta \cdot \sum_{i, p, t}\left(d_{i p}^{(4) t}-(1-\alpha) d_{i p}^{(3) t}-\alpha \cdot d_{i p}^{(4) t}\right.
\end{aligned}
$$

Changed constraints

$$
\sum_{\substack{o \\ \forall i, p, t, s}} q o_{p o i}^{t, s} \geq(1-\alpha) \cdot d_{i p}^{(3) t}+\alpha \cdot d_{i p}^{(4) t} \quad ; 0.5 \leq \alpha \leq 1
$$

The remainder of the restrictions remain the same as in the previous iteration. Such terms allow the model to refine the trust level of the constraints and do not require several time-consuming checks to assess the trust rates that have become available in conventional programming models. In fact, the optimization of trust rates with the phrases listed above is assured in this process.

\section{Model Implementation and Evaluation}

In this section, in order to demonstrate the applicability of the developed model, as well as to evaluate the effectiveness of the developed model, the data comes from a case study of a supply chain of drug manufacturing company. In total, 9 types of raw materials were purchased from external suppliers and eventually converted into 6 final products.

In the current modeling, planning has been done over 12 periods. The information available is as described in tables 2 and 3. The probability of each occurring scenario is shown in the table 4 . The financial limits used are described in table 5 and exchange rate fluctuations over the period are also described in table 6.

Table 2. $h_{j s}$ parameter value

\begin{tabular}{lllll}
\hline \multicolumn{2}{l}{$h_{j s}$} & & & \\
& $\mathbf{1}^{2}$ & $\mathbf{2}$ & $\mathbf{3}$ & $\mathbf{4}$ \\
\hline 1 & & & & \\
2 & & & & \\
3 & & & & \\
4 & & & & \\
5 & & & & \\
\hline
\end{tabular}


Table 3. $a_{j s}$ parameter value

\begin{tabular}{lllll}
\hline$h_{j s}$ & & & \\
& $\mathbf{1}$ & $\mathbf{2}$ & $\mathbf{3}$ & $\mathbf{4}$ \\
\hline 1 & & & & \\
2 & & & & \\
3 & & & & \\
4 & & & & \\
5 & & & & \\
\hline
\end{tabular}

Table 4. The probability of occurring each scenario

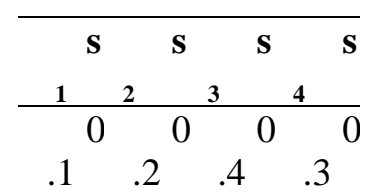

Table 5. Financial parameters limit

\begin{tabular}{|l|c|}
\hline \multicolumn{1}{|c|}{ Financial parameters } & $\begin{array}{r}\text { V } \\
\text { alue }\end{array}$ \\
\hline Current Ratio & 2 \\
Instant ratio & 1. \\
Available money rates & 25 \\
Fixed asset turnover rate & 1 \\
Turnover ratio of received & 1. \\
accounts & 1 \\
Total Debt Rate & 1. \\
Equity Debt Rate & 6 \\
The upper limit on long-term & 0. \\
debt & 6 \\
Money Coverage Rate & 1. \\
Return on Assets & 5 \\
Equity Return Rate & 0. \\
& 8 \\
& 5 \\
& 0. \\
& 0. \\
\hline
\end{tabular}

Table 6. Exchange rate fluctuations over the period 
Figures 1, 2, 3 and 4 show the estimation of American calls at different strike costs, time to lapse and yearly unpredictability of the basic resource. The error bars in both statistics indicate the size of two standard deviations of the reward calculated by more than 30 tries. $K=100,000$ forms and $M=200$ containers were used for each ride. Tests have shown that the valuation blunder in the suggested method is minimal and is equal to the mistake in utilizing SSAP. Therefore, the standard deviation of the errors stays truly stable as the rate of production of the critical resource rises.
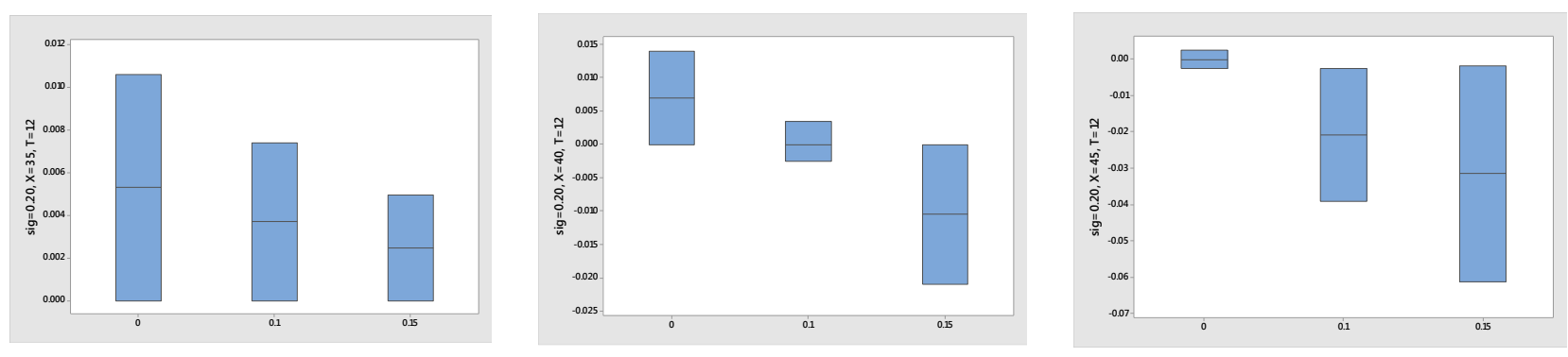

Figure 1. American call option: Valuation mistake vs. constant time approach vs. inherent asset risk premium $\left(\sigma=0.20, X=35,40,45, T=12\right.$ months, $\left.\mathrm{S}_{0}=4, r_{f}=0.05, \delta t=\mathrm{T} / 10\right)$
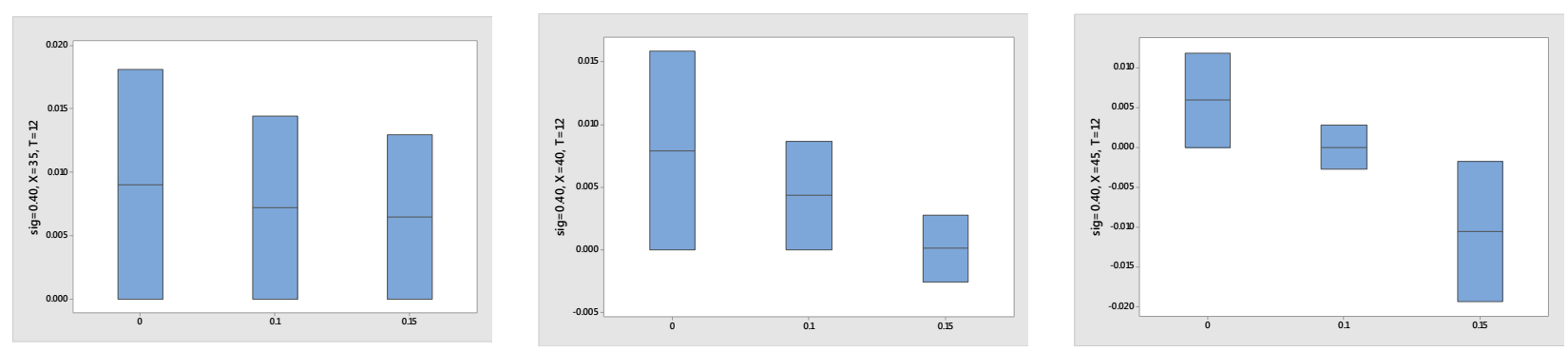

Figure 2. American call option: Valuation mistake vs. constant time approach vs. inherent asset risk premium $\left(\sigma=0.40, \mathrm{X}=35,40,45, \mathrm{~T}=12\right.$ months, $\left.\mathrm{S}_{0}=40, r_{f}=0.05, \delta t=\mathrm{T} / 10\right)$ 

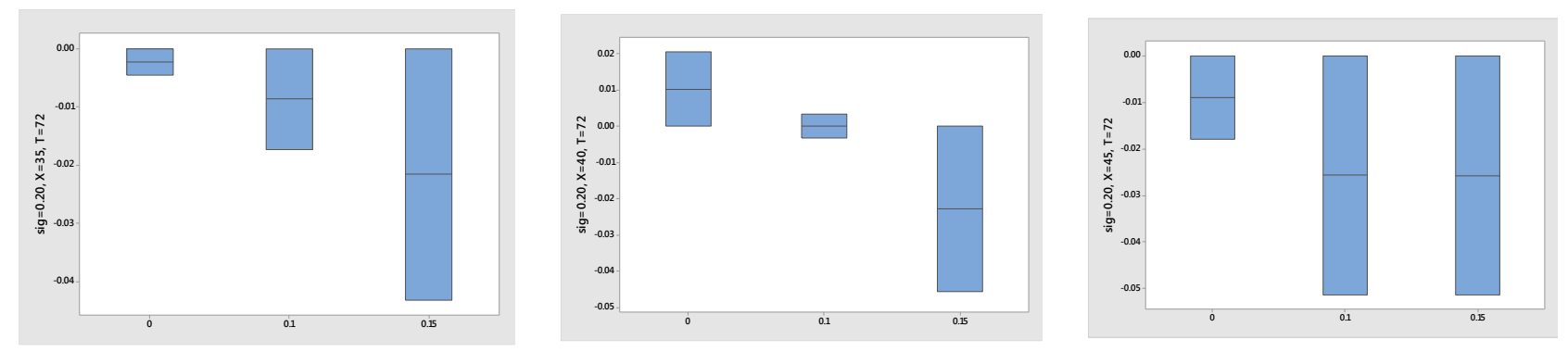

Figure 3. American call option: Valuation mistake vs. constant time approach vs. inherent asset risk premium $\left(\sigma=0.20, \mathrm{X}=35,40,45, \mathrm{~T}=72\right.$ months, $\left.\mathrm{S}_{0}=40, r_{f}=0.05, \delta t=\mathrm{T} / 10\right)$
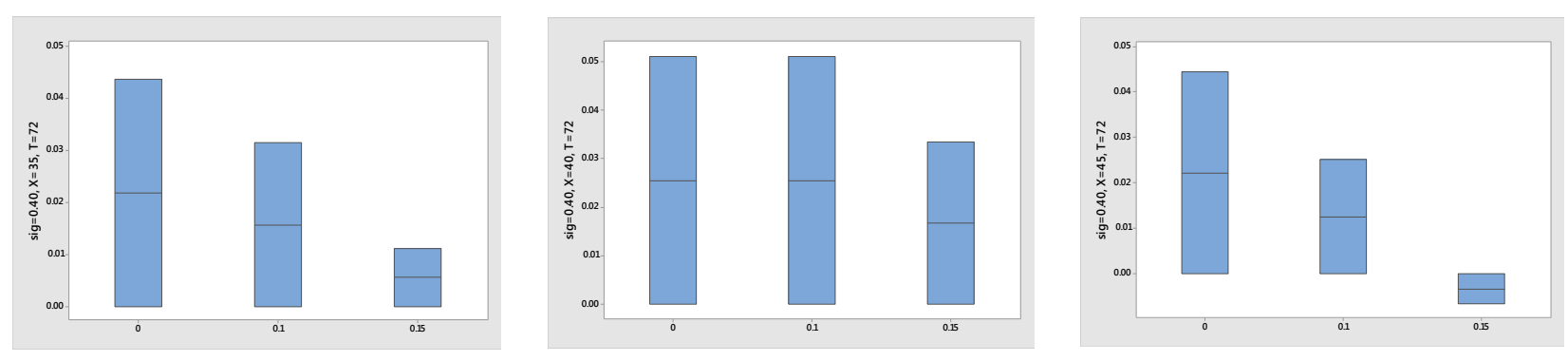

Figure 4. American call option: Valuation mistake vs. constant time approach vs. inherent asset risk premium $\left(\sigma=0.40, \mathrm{X}=35,40,45, \mathrm{~T}=72\right.$ months, $\mathrm{S}_{0}=40, r_{f}=0.05, \delta t=\mathrm{T} / 10$ )

\subsection{Valuation of non-correlated states}

The current value and estimation method blends adaptability and leisure duration with later predicted results that maximize the value of options using true probability spreads. The theoretical assessment of such a method was discussed above: it includes bringing the ideas of concrete alternatives to the investigator much more productively and to a broader audience; it enables the re-enactment to be done clearly because it is used in actual construction practice; and it has the capacity to enhance the present act of esteeming building systems as it is presented. Again, the assessment method is inaccurate and inappropriate from a financial point of view because elective policies and states are not strongly related. The purpose of this field is to analyze how this approach compares, from a conceptual point of view, with the variations of old-style actual alternatives being studied, as measured in Borison [7]. The purpose of this inquiry was to evaluate elective plans (states) and alternatives accurately as demonstrated by their relative danger. In do so, the analysis recommended that the usual return of both advantages and alternatives (in this case, their markdown rate) would lie on a straight line in $r \times \sigma$ space [34].

From the point of view of the Capital Asset Pricing Model (CAPM), that is a self-defeated assumption that all systems are ideally associated, in the light of the reality that the proportion of the standard variance of income for various commodities is equal to the proportion of their "betas" with the reference state. To put it simply, the strategy offers a steady assessment of all the incentives and opportunities on the off risk that all the advantages are completely integrated at some stage. The premise that is not ridiculous: the development of various systems requires phases whose values depend on similar unknown flaws in the same way.

In fact, because the comparison structure is essentially calculated from the point of view of the extended financial expert, i.e. $V_{r e f}$ is the market assessment of the comparison venture, at this stage the market valuation of each other State would therefore be their market valuation (or the interest they will trade on the market, at the probability that they were currently built). In this case, the process is both straightforward and correct from a stock valuation point of view. 
The current model is modeled in GAMS optimization software and its results are as follows. Model implementation results show that all six products must be born in all periods and scenarios, and the numbers are determined in such a way that there is no discard of the products produced. This also relates to the limitation of suppliers' ability to supply raw materials to what extent they can meet the needs of the manufacturer at any given time. The amount of production per period and scenario for each product is described in table 7.

Table 7. Amount of production per period and scenario for each product $(\mathrm{kg})$

\begin{tabular}{|c|r|r|r|r|}
\hline$q p_{p o}^{t, s}$ & $\mathrm{~S}_{1}$ & $\mathrm{~S}_{2}$ & $\mathrm{~S}_{3}$ & $\mathrm{~S}_{4}$ \\
\hline 1.1 .1 to & 7 & 7 & 7 & 7 \\
1.1 .12 & 07.5 & 07.5 & 07.5 & 07.5 \\
\hline 2.1 .1 to & 3 & 3 & 3 & 3 \\
2.1 .12 & 12.5 & 12.5 & 12.5 & 12.5 \\
\hline 3.1 .1 to & 1 & 1 & 1 & 1 \\
3.1 .12 & 02 & 02 & 02 & 02 \\
\hline 4.1 .1 to & 1 & 1 & 1 & 1 \\
4.1 .12 & 88.5 & 88.5 & 88.5 & 88.5 \\
\hline 5.1 .1 to & 9 & 9 & 9 & 9 \\
5.1 .12 & 55 & 55 & 55 & 55 \\
\hline 6.1 .1 to & 7 & 7 & 7 & 7 \\
6.1 .12 & 5 & 5 & 5 & 5 \\
\hline
\end{tabular}

The results of supplier-to-producer selection indicate that suppliers have less risk and at the same time lower costs. For example, between the second and fourth suppliers, both of which have the same shipping costs, the flow from the second supplier to the manufacturer is shifted to a larger amount due to the lower risk of this supplier.

The results do not confirm the problem of being single-source and dependent on a supplier, and argue that suppliers should be purchased at low risk and at a low cost. Also, due to the long life span for raw materials, the purchase of these materials has occurred throughout the period and has been avoided altogether.

It generally establishes a balance between the cost of transportation and the risk of access that each supplier has in different scenarios, and determines their flows and quantities in the most optimal way. The results obtained for the supply chain indicate that the system is resilient in the face of possible scenarios. Due to the shelf life of raw materials, it is recommended to maintain low reliability storage in the system, as raw material corruption will result in higher costs to the collection.

The following method is used to simulate and validate the model. Initially, for every nonlinear parameter that has a trapezoidal probability function $\beta=\left(\beta^{(1)}, \beta^{(2)}, \beta^{(3)}, \beta^{(4)}\right)$, a random number is generated uniformly between the beginning and end points of the probability function $\beta_{\text {real }}=\left[\beta^{(1)}, \beta^{(4)}\right]$. Then, in order to evaluate the feasibility of the outputs of the possibility programming and robust possibility programming in combination with the real options approach and to compare their results, the parameters produced under each simulation are specified under nominal data and included in the model. 


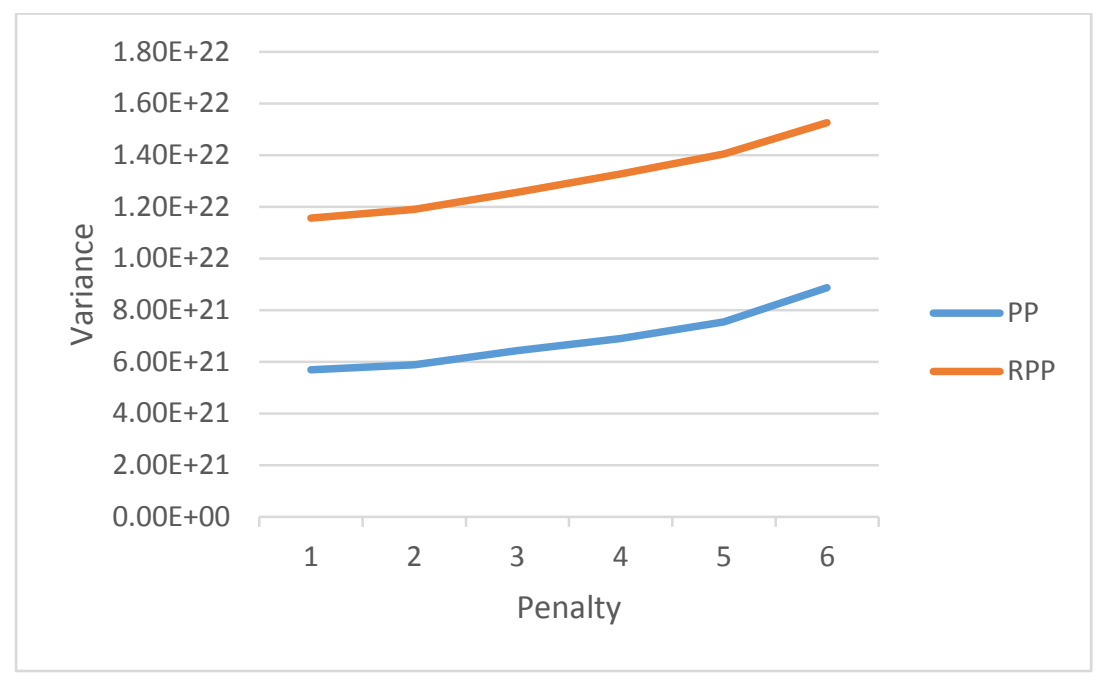

Figure 5. The amount of variance of possibility programming and robust possibility programming under different penalties

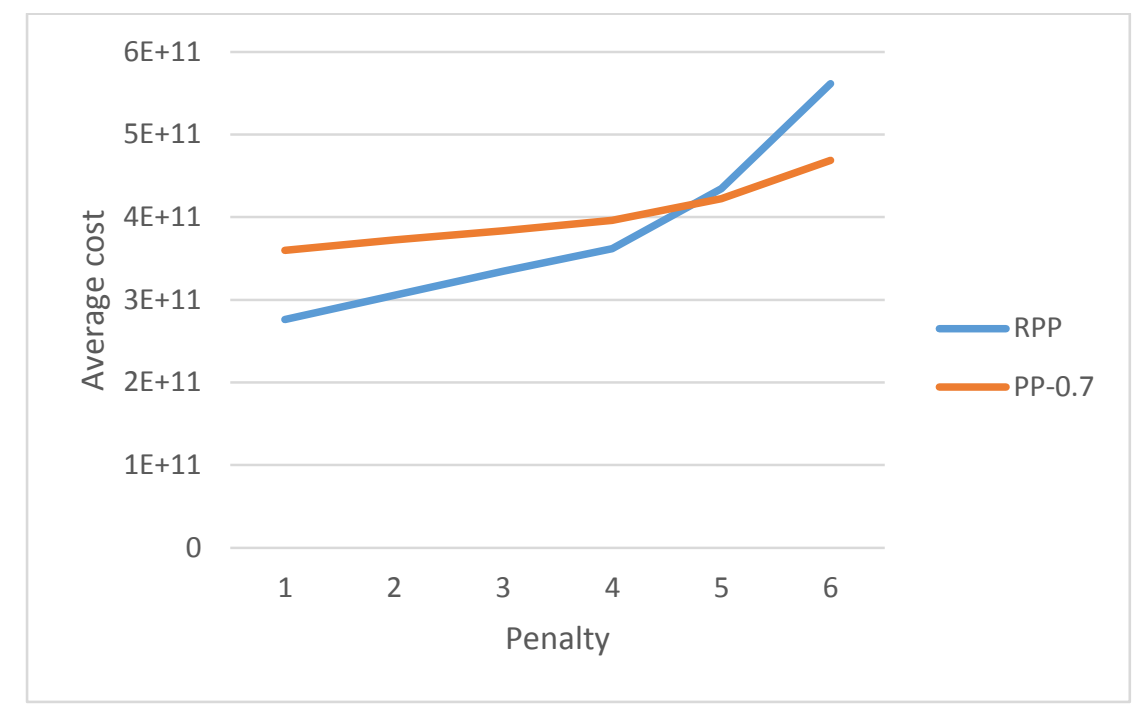

Figure 6. Average value of the possibility programming and robust possibility programming objective function under different penalties

The point made in figure 5 is that the lower variance of the robust possibility programming model, which is always greater than the possibility planning model under varying levels of confidence. It is also worth noting that increasing fines increases the variance, but the feasibility of a robust possibility programming model has always been maintained.

In addition to the standard deviation, the mean of the target distributions needs to be taken into account. This is also illustrated in Figure 6. As it is known, the mean value of the robust possibility programming objective function in the lower fines is less than the mean value of the possibility programming at the confidence level of 0.7 .

The robust possibility programming model is a risk averse model, but it avoids unnecessary conservatism. Due to the level of risk aversion created by the robust possibility programming model, the outputs of this model are less risky and less violations than possibility programming models - under low fines. Therefore, it can be acknowledged that the solid model presented in this study can effectively help managers to have proper planning in response to this crisis under sanctions. 


\section{Conclusions}

The purpose of this paper was to include an introduction to the amount of versatility of institutionalized development programs. The chosen approach for this was real solutions, because of the bad entry it has provided so far to experts and artists. This segment suggests a modern interactive interface for plotting the strategy and optimizing choices, as well as a separate valuation method for these choices. It is expected that these two actions would have the potential to put concrete solutions closer to building reality, even as the standardization and consistency of the service schedule would be encouraged.

In recent decades, exchanges between different countries have been increasing and supply chains have moved towards globalization, which has affected the laws of different countries and consequently increased the complexity and vulnerability of the chain. One of the reasons that has caused so much damage is the lack of robustness of the system and the lack of proper planning to deal with this phenomenon, which has not been precisely simulated at this time, and this study aims to model this problem in drug supply chains. After robust supply chain modeling, it has shown how it can be influenced by possible planning through mean of objective function and variance factors.

The main factor in model performance and the determination of confidence levels of nonlinear parameters are fines. To determine these parameters, it is best to have a set of inexperienced managers of the organization based on past experience as well as available data on the past performance of the organization and the degree of uncertainty of the parameters and their importance. Model outputs also indicate that under any circumstances it is better to choose suppliers with less risk; that is, risk takes priority over shipping costs.

\section{References}

[1] Acar, Y., S. Kadipasaoglu, and P. Schipperijn, A decision support framework for global supply chain modelling: an assessment of the impact of demand, supply and lead-time uncertainties on performance. International Journal of Production Research, 2010. 48(11): p. 3245-3268.

[2] Ackoff, R.L., The art and science of mess management. Interfaces, 1981. 11(1): p. 20-26.

[3] Amram, M. and N. Kulatilaka, Real options:: Managing strategic investment in an uncertain world. OUP Catalogue, 1998.

[4] Arnold, T. and T.F. Crack, Option pricing in the real world: a generalized binomial model with applications to real options. Available at SSRN 240554, 2000.

[5] Barraquand, J. and D. Martineau, Numerical valuation of high dimensional multivariate American securities. Journal of financial and quantitative analysis, 1995. 30(3): p. 383-405.

[6] Bennett, D., P. Forrester, and J. Hassard, An application of decision process modelling to manufacturing system design. Omega, 1990. 18(1): p. 23-33.

[7] Borison, A., Real options analysis: Where are the emperor's clothes? Journal of applied corporate finance, 2005. 17(2): p. 17-31.

[8] Brealey, R.A., et al., Principles of corporate finance. 2012: Tata McGraw-Hill Education.

[9] Broadie, M. and J. Detemple, The valuation of American options on multiple assets. Mathematical Finance, 1997. 7(3): p. 241-286.

[10] Broadie, M. and P. Glasserman, Pricing American-style securities using simulation. Journal of economic dynamics and control, 1997. 21(8-9): p. 1323-1352.

[11] Chopra, S. and P. Meindl, Supply chain management. Strategy, planning \& operation, in Das summa summarum des management. 2007, Springer. p. 265-275.

[12] Cox, J.C., S.A. Ross, and M. Rubinstein, Option pricing: A simplified approach. Journal of financial Economics, 1979. 7(3): p. 229-263.

[13] D'Souza, B. and T.W. Simpson*, A genetic algorithm based method for product family design optimization. Engineering Optimization, 2003. 35(1): p. 1-18. 
[14] de Castro Vivas, R., et al., Integrated method combining analytical and mathematical models for the evaluation and optimization of sustainable supply chains: A Brazilian case study. Computers \& Industrial Engineering, 2020. 139: p. 105670.

[15] de Neufville, R., Architecting/designing engineering systems using real options. 2002.

[16] De Neufville, R., S. Scholtes, and T. Wang, Real options by spreadsheet: parking garage case example. Journal of infrastructure systems, 2006. 12(2): p. 107-111.

[17] de Weck, O., R. de Neufville, and M. Chaize. Enhancing the economics of communication satellites via orbital reconfigurations and staged deployment. in AIAA Space 2003 Conference \& Exposition. 2003.

[18] Dixit, A.K., R.K. Dixit, and R.S. Pindyck, Investment under uncertainty. 1994: Princeton university press.

[19] ElMaraghy, H.A. and N. Mahmoudi, Concurrent design of product modules structure and global supply chain configurations. International Journal of Computer Integrated Manufacturing, 2009. 22(6): p. 483-493.

[20] Eppinger, S. and K. Ulrich, Product design and development. 2015: McGraw-Hill Higher Education.

[21] Fazli-Khalaf, M., S.K. Chaharsooghi, and M.S. Pishvaee, A new robust possibilistic programming model for reliable supply chain network design: A case study of lead-acid battery supply chain. RAIRO-Operations Research, 2019. 53(5): p. 1489-1512.

[22] Fricke, E. and A.P. Schulz, Design for changeability (DfC): Principles to enable changes in systems throughout their entire lifecycle. Systems Engineering, 2005. 8(4): p. no-no.

[23] Fujita, M., P.R. Krugman, and A. Venables, The spatial economy: Cities, regions, and international trade. 1999: MIT press.

[24] Goh, M., J.Y. Lim, and F. Meng, A stochastic model for risk management in global supply chain networks. European Journal of Operational Research, 2007. 182(1): p. 164-173.

[25] Greden, L. and L. Glicksman, A real options model for valuing flexible space. Journal of Corporate Real Estate, 2005. 7(1): p. 34-48.

[26] Hadjinicola, G.C. and K.R. Kumar, Modeling manufacturing and marketing options in international operations. International Journal of Production Economics, 2002. 75(3): p. 287-304.

[27] Hasani, A., S.H. Zegordi, and E. Nikbakhsh, Robust closed-loop global supply chain network design under uncertainty: the case of the medical device industry. International Journal of Production Research, 2015. 53(5): p. 1596-1624.

[28] Hasani, A. and A. Khosrojerdi, Robust global supply chain network design under disruption and uncertainty considering resilience strategies: A parallel memetic algorithm for a real-life case study. Transportation Research Part E: Logistics and Transportation Review, 2016. 87: p. 20-52.

[29] Hendricks, K. and V.R. Singhal, The effect of supply chain disruptions on long-term shareholder value, profitability, and share price volatility. Supply Chain Magazine, 2005.

[30] Hull, J.C., Options futures and other derivatives. 2003: Pearson Education India.

[31] Hushmandi Maher, M., M. Amiri, and L. Olfat, Mathematical model of supplier selection and order allocation in the supply chain considering the uncertainties in design variables. Journal of Industrial Management. 6(1): p. 151-180.

[32] Ibanez, A. and F. Zapatero, Monte Carlo valuation of American options through computation of the optimal exercise frontier. Journal of Financial and Quantitative Analysis, 2004. 39(2): p. 253-275.

[33] Kalligeros, K. and O. De Weck. Flexible design of commercial systems under market uncertainty: Framework and application. in 10th AIAA/ISSMO Multidisciplinary Analysis and Optimization Conference. 2004.

[34] Kalligeros, K.C., Platforms and real options in large-scale engineering systems. 2006, Massachusetts Institute of Technology.

[35] Khalilpourazari, S., S.H.R. Pasandideh, and A. Ghodratnama, Robust possibilistic programming for multi-item EOQ model with defective supply batches: Whale Optimization and Water Cycle Algorithms. Neural Computing and Applications, 2019. 31(10): p. 6587-6614.

[36] Kidd, J. and S. Prabhu, A practical example of a multi-attribute decision aiding technique. Omega, 1990. 18(2): p. 139-149. 
[37] Kim, M. and S. Chai, The impact of supplier innovativeness, information sharing and strategic sourcing on improving supply chain agility: Global supply chain perspective. International Journal of Production Economics, 2017. 187: p. 42-52.

[38] Liu, S. and L.G. Papageorgiou, Multiobjective optimisation of production, distribution and capacity planning of global supply chains in the process industry. Omega, 2013. 41(2): p. 369-382.

[39] Longstaff, F.A. and E.S. Schwartz, Valuing American options by simulation: a simple least-squares approach. The review of financial studies, 2001. 14(1): p. 113-147.

[40] Markish, J. and K. Willcox. A value-based approach for commercial aircraft conceptual design. in Proceedings of the ICAS2002 Congress, Toronto. 2002.

[41] Merton, R.C., Theory of rational option pricing. Theory of Valuation, 1973: p. 229-288.

[42] Miller, T. and R. De Matta, A global supply chain profit maximization and transfer pricing model. Journal of Business Logistics, 2008. 29(1): p. 175-199.

[43] Mingers, J., Variety is the spice of life: combining soft and hard OR/MS methods. International Transactions in Operational Research, 2000. 7(6): p. 673-691.

[44] Myers, S.C., Finance theory and financial strategy. Interfaces, 1984. 14(1): p. 126-137.

[45] Nagurney, A., J. Cruz, and D. Matsypura, Dynamics of global supply chain supernetworks. Mathematical and Computer Modelling, 2003. 37(9-10): p. 963-983.

[46] Narasimhan, R. and S. Mahapatra, Decision models in global supply chain management. Industrial Marketing Management, 2004. 33(1): p. 21-27.

[47] Neufville, R., Real options: dealing with uncertainty in systems planning and design. Integrated Assessment, 2003. 4(1): p. 26-34.

[48] Peck, H., Drivers of supply chain vulnerability: an integrated framework. International journal of physical distribution \& logistics management, 2005. 35(4): p. 210-232.

[49] Perron, S., et al., Exact and heuristic solutions of the global supply chain problem with transfer pricing. European Journal of Operational Research, 2010. 202(3): p. 864-879.

[50] Raymar, S.B. and M.J. Zwecher, Monte Carlo estimation of American call options on the maximum of several stocks. Journal of Derivatives, 1997. 5(1): p. 7.

[51] Rosenhead, J., Planning under uncertainty: 1. The inflexibility of methodologies. Journal of the Operational Research Society, 1980. 31(3): p. 209-216.

[52] Rosenhead, J. and J. Mingers, Rational analysis for a problematic world revisited: Problem structuring methods for complexity, uncertainty and conflict. 2001: Wiley Chichester.

[53] Sawik, T., Two-period vs. multi-period model for supply chain disruption management. International Journal of Production Research, 2019. 57(14): p. 4502-4518.

[54] Schultz, M., C. Schulz, and H. Fricke, Pedestrian and Evacuation Dynamics. 2005, Beitrag: A discrete microscopic model for pedestrian dynamics to manage ....

[55] Siddique, Z. and D.W. Rosen, On combinatorial design spaces for the configuration design of product families. AI EDAM, 2001. 15(2): p. 91-108.

[56] Singh, A.R., et al., Design of global supply chain network with operational risks. The International Journal of Advanced Manufacturing Technology, 2012. 60(1-4): p. 273-290.

[57] Smith, J.E. and K.F. McCardle, Valuing oil properties: integrating option pricing and decision analysis approaches. Operations Research, 1998. 46(2): p. 198-217.

[58] Song, H. and X. Gao, Green supply chain game model and analysis under revenue-sharing contract. Journal of Cleaner Production, 2018. 170: p. 183-192.

[59] Sounderpandian, J., S. Prasad, and M. Madan, Supplies from developing countries: optimal order quantities under loss risks. Omega, 2008. 36(1): p. 122-130.

[60] Sousa, R.T., et al., Global supply chain planning for pharmaceuticals. Chemical Engineering Research and Design, 2011. 89(11): p. 2396-2409.

[61] Sun, J., Global production planning with fuzzy exchange rates. Journal of Uncertain Systems, 2014. 8(1): p. 58-65.

[62] Tang, C.S., Perspectives in supply chain risk management. International journal of production economics, 2006. 103(2): p. 451-488. 
[63] Thorlakson, T., J.F. de Zegher, and E.F. Lambin, Companies' contribution to sustainability through global supply chains. Proceedings of the National Academy of Sciences, 2018. 115(9): p. 20722077.

[64] Tilley, J.A. Valuing American options in a path simulation model. in Transactions of the Society of Actuaries. 1993. Citeseer.

[65] Vidal, C.J. and M. Goetschalckx, A global supply chain model with transfer pricing and transportation cost allocation. European Journal of Operational Research, 2001. 129(1): p. 134-158.

[66] Wang, T., Real options" in" projects and systems design: identification of options and solutions for path dependency. 2005, Massachusetts Institute of Technology.

[67] Wang, T. and R. De Neufville. Real options "in" projects. in real options conference, Paris, France. 2005. Citeseer.

[68] Wu, T., J. Blackhurst, and P. O'grady, Methodology for supply chain disruption analysis. International journal of production research, 2007. 45(7): p. 1665-1682.

[69] You, F., J.M. Wassick, and I.E. Grossmann, Risk management for a global supply chain planning under uncertainty: models and algorithms. AIChE Journal, 2009. 55(4): p. 931-946.

[70] Yu, T.-L., D.E. Goldberg, and K. Sastry. Optimal sampling and speed-up for genetic algorithms on the sampled onemax problem. in Genetic and Evolutionary Computation Conference. 2003. Springer.

[71] Yun, Y., A. Chuluunsukh, and M. Gen, Sustainable Closed-Loop Supply Chain Design Problem: A Hybrid Genetic Algorithm Approach. Mathematics, 2020. 8(1): p. 84.

[72] Zhao, T. and C.-L. Tseng, Valuing flexibility in infrastructure expansion. Journal of infrastructure systems, 2003. 9(3): p. 89-97.

\section{Appendix: Options valuation formula}

In the beginning, it was hypothesized that the reason of existing valuation hypothesis, i.e., the capacity to support on the basic resource and the absence of exchange, is a piece of the explanation that the real options strategy has not picked up footing with fashioners and engineers. In the proposed procedure, a solitary reference state is esteemed utilizing the building up association's standard practices. The reference state 
relates to the base case plan, i.e., the arrangement the engineer would consider before any conversation about adaptability. This valuation certainly gives the association's hazard resistance towards the uncertainties $s_{t}$ overseeing the framework's worth.

Conversely with the current recreation calculations, the proposed strategy includes reproduction of this present reality elements of the basic uncertainties $s_{t}$, valuation of a reference configuration dependent on its normal future incomes barring any adaptability. Consider a reference structure, its comparing state and a specially appointed satisfactory markdown rate $r_{\text {ref }}$ for this plan. The estimation of this state $V_{\text {ref }}$ as of time to with no decision or timing options is equivalent to

$$
V_{r e f}\left(s_{0}\right)=\sum_{t=t_{0}}^{T} e^{-r_{r e f} t} E\left[C F_{r e f}\left(\overline{s_{t}}\right)\right]
$$

where the desire is assumed control over all receptacles $n$ at each time $t$. For the valuation of the reference structure, it very well may be determined as appeared in equation 19 .

$$
\lambda=\frac{e^{r_{r e f} \delta t}-e^{r_{f} \delta t}}{\sigma_{r e f}}
$$

To esteem another state $w$, whose worth is impeccably associated with the reference structure, the designer has two clear options for the rebate rate: (a) they may utilize the reference markdown rate $r_{r e f}$, or (b) utilize a similar cost of hazard. Practically speaking, the firm-wide WACC is quite often used to esteem all plans. Nonetheless, except if the reference state and state $w$ have no distinctions in chance presentation to $s_{t}$, utilizing the WACC for both suggests an irregularity, i.e., that the engineer is apathetic regarding the vulnerability in future qualities. The estimation of structure $w$ can be composed as a certainty-equivalent as follows:

$$
\begin{aligned}
& V_{w}\left(s_{t}\right)=e^{-r_{w} \delta t} E\left[V_{w}\left(\bar{s}_{t+\delta t}\right)\right] \\
& \Rightarrow\left(e^{r_{w} \delta t}+e^{r_{f} \delta t}-e^{r_{f} \delta t}\right) V_{w}\left(s_{t}\right)=E\left[V_{w}\left(\bar{s}_{t+\delta t}\right)\right] \\
& \Rightarrow\left(e^{r_{w} \delta t}-e^{r_{f} \delta t}\right) V_{w}\left(s_{t}\right)+e^{r_{f} \delta t} V_{w}\left(s_{t}\right)=E\left[V_{w}\left(\bar{s}_{t+\delta t}\right)\right]
\end{aligned}
$$

Which means

$$
\begin{aligned}
V_{w}\left(s_{t}\right) & =e^{-r_{f} \delta t}\left[E\left[V_{w}\left(\bar{s}_{t+\delta t}\right)\right]-\left(e^{r_{w} \delta t}-e^{r_{f} \delta t}\right) V_{w}\left(s_{t}\right)\right] \\
& =e^{-r_{f} \delta t} C E Q\left[V_{w}\left(\bar{s}_{t+\delta t}\right)\right]
\end{aligned}
$$

Equation 21 shows that a similar present worth can be acquired either by limiting the real expected an incentive at a rate that mirrors the hazard natural in the desire, or by lessening the future expected an incentive by a specific sum that relies upon its hazard, and than limiting it at the hazard free rate. Holding the cost of hazard steady between the valuation of the reference plan and $w$ implies

$$
\lambda=\frac{e^{r_{r e f} \delta t}-e^{r_{f} \delta t}}{\sigma_{r e f}}=\frac{e^{r_{w} \delta t}-e^{r_{f} \delta t}}{\sigma_{w}}
$$

It follows that 


$$
\left(e^{r_{w} \delta t}-e^{r_{f} \delta t}\right) V_{w}\left(\overline{s_{t}}\right)=\frac{\sigma\left[V_{w}\left(\overline{s_{t+\delta t}}\right)\right]}{\sigma\left[V_{r e f}\left(\bar{s}_{t+\delta t}\right)\right]} V_{r e f}\left(\overline{s_{t}}\right)\left(e^{r_{r e f} \delta t}-e^{r_{f} \delta t}\right)
$$

Substituting Equation 23 into 21 yields the estimation of $w$ given the hazard resistance acquired from esteeming the reference structure:

$$
V_{w}\left(\bar{s}_{t}\right)=e^{-r_{f} \delta t}\left[E\left[V_{w}\left(\bar{s}_{t+\delta t}\right)\right]-\left(e^{r_{r e f} \delta t}-e^{r_{f} \delta t}\right) V_{r e f}\left(\bar{s}_{t}^{m}\right) \frac{\sigma\left[V_{w}\left(\bar{s}_{t+\delta t}\right)\right]}{\sigma\left[V_{r e f}\left(\overline{s_{t+\delta t}}\right)\right]}\right]
$$

Condition 24 can be utilized straightforwardly with the state collection conspire depicted in the past segment for the recursive valuation of structure $w$. For each container $m$ at time $t$, the normal estimation of $w$ in whenever step over all the receptacles $n$ in time step is appeared in Equation 25. The standard deviation of given $V_{w}\left(\bar{s}_{t+\delta t}\right)$ is meant $\underset{m}{\sigma}\left[V_{w}\left(\bar{s}_{t+\delta t}\right)\right]$ and is determined easily in Equation 26.

$$
\begin{aligned}
\underset{m}{E}\left[V_{w}\left(\bar{s}_{t+\delta t}\right)\right] & =\sum_{n} P_{t}(m, n) V_{w}\left(\bar{s}_{t+\delta t}^{n}\right) \\
\underset{m}{\sigma}\left[V_{w}\left(\overline{s_{t+\delta t}}\right)\right] & =\sqrt{\underset{m}{E\left[V_{w}\left(\overline{s_{t+\delta t}}\right)^{2}\right]-E_{m}^{E}\left[V_{w}\left(\overline{s_{t+\delta t}}\right)\right]^{2}}} \\
& =\sqrt{\sum_{n} P_{t}(m, n) V_{w}\left(\bar{s}_{t+\delta t}^{n}\right)^{2}-\left(\sum_{n} P_{t}(m, n) V_{w}\left(\bar{s}_{t+\delta t}^{n}\right)\right)^{2}}
\end{aligned}
$$

The estimation of a planning choice to acquire state $w$ in return for the estimation of $\mathrm{u}$ and the improvement cost is impeccably associated with the distinction $V_{w}\left(\bar{s}_{t}\right)-V_{u}\left(\bar{s}_{t}\right)$, if $u$ and $w$ are perfectly correlated. In this way, in the event that the two states $u$ and $w$ are impeccably connected between them, at that point the examination in the past area applies and the benefit of holding the option alive can be assessed recursively utilizing Equations 24, 25 and 26.

Then again, if the two states are perfectly correlated, it is possible that one can be utilized as a kind of perspective case. Additionally, on the off chance that they are both splendidly corresponded with another reference state $V_{\text {ref }}$, at that point that worth can be utilized as a kind of perspective. So by and large, the benefit of holding the choice in container $m$ at time $t$ is evaluated as:

$$
O\left(\bar{s}_{t}^{m}\right)=e^{-r_{f} \delta t}\left[\underset{m}{E}\left[F_{u w}\left(\bar{s}_{t+\delta t}\right)\right]-\left(e^{r_{r f} \delta t}-e^{r_{f} \delta t}\right) V_{r e f}\left(\bar{s}_{t}^{m}\right) \underset{\underset{m}{\sigma}\left[V_{r e f}\left(\bar{s}_{t+\delta t}\right)\right]}{\sigma\left[F_{u w}\left(\overline{s_{t}}\right)\right]}\right]
$$

